\title{
Current-Voltage Characteristics of the Composites Based on Epoxy Resin and Carbon Nanotubes
}

\author{
Iwona Pełech, ${ }^{1}$ Agnieszka Kaczmarek, ${ }^{1}$ and Robert Pełech ${ }^{2}$ \\ ${ }^{1}$ Institute of Chemical and Environment Engineering, West Pomeranian University of Technology, \\ Pułaskiego 10, 70-322 Szczecin, Poland \\ ${ }^{2}$ Institute of Organic Chemical Technology, West Pomeranian University of Technology, Pułaskiego 10, 70-322 Szczecin, Poland
}

Correspondence should be addressed to Iwona Pełech; ipelech@zut.edu.pl

Received 20 October 2014; Revised 7 January 2015; Accepted 8 January 2015

Academic Editor: Bo Tan

Copyright (C) 2015 Iwona Pełech et al. This is an open access article distributed under the Creative Commons Attribution License, which permits unrestricted use, distribution, and reproduction in any medium, provided the original work is properly cited.

\begin{abstract}
Polymer composites based on epoxy resin were prepared. Multiwalled carbon nanotubes synthesized on iron-cobalt catalyst were applied as a filler in a polymer matrix. Chlorine or hydroxyl groups were incorporated on the carbon nanotubes surface via chlorination or chlorination followed by hydroxylation. The effect of functionalized carbon nanotubes on the epoxy resin matrix is discussed in terms of the state of CNTs dispersion in composites as well as electrical properties. For the obtained materials currentvoltage characteristics were determined. They had a nonlinear character and were well described by an exponential-type equation. For all the obtained materials the percolation threshold occurred at a concentration of about $1 \mathrm{wt} \%$. At a higher filler concentration $>2 \mathrm{wt} \%$, better conductivity was demonstrated by polymer composites with raw carbon nanotubes. At a lower filler concentration $<2 \mathrm{wt} \%$, higher values of electrical conductivity were obtained for polymer composites with modified carbon nanotubes.
\end{abstract}

\section{Introduction}

Epoxy resins are used as high performance polymers because of their excellent mechanical properties, chemical resistance, thermal stability, and low production costs. They are commonly used as surface coatings, electrical insulation materials, adhesives, and glues. However, there are many cases where enhanced electrical conductivity of polymeric materials is needed in an electromagnetic shield to prevent electrostatic charging of electronic devices. Good unique electrical and structural properties of carbon nanotubes (CNT) and their high aspect ratio enable the formation of electrical conducting paths in the polymer matrix at a very small percolation concentration $[1,2]$. In the case of $\mathrm{CNT} /$ polymer composites the main problem is to create a good homogeneous dispersion of nanotubes in the polymer matrix in spite of van der Waals interactions in nanotubes [3]. To improve interfacial bonding and the dispersion of nanotubes in the polymer matrix, chemical functionalization of CNT is commonly used $[4,5]$. It was reported that epoxy composites filled with well dispersed CNT provided much higher values of electrical and thermal conductivity than samples with poor dispersion [6-8]. In the literature there can be found reports on the reduction of percolation threshold for composites based on functionalized multiwalled carbon nanotubes (MWCNTs) and epoxy resin [9]. On the other hand, although covalent functionalization could be detrimental to the electrical conductivity of nanotubes [10-12], it does not always translate into a deterioration of conductivity of composites filled by functionalized CNT.

In this study we present a preparation method of polymer composites based on epoxy resin and multiwalled carbon nanotubes. In the first stage carbon nanotubes were subjected to chlorination in the gas phase followed by the treatment with sodium hydroxide to induce chlorine and/or hydroxyl groups on the CNT surface. The effect of carbon nanotube functionalization on the epoxy resin matrix is discussed in terms of electrical properties as well as the state of CNT dispersion in composites.

\section{Experimental}

Multiwalled carbon nanotubes were prepared on an ironcobalt catalyst (which will be referred to as CNT). Details of 
catalyst preparation were reported elsewhere [13]. The synthesis of CNT was carried out in a high-temperature furnace (HST 12/400 Carbolite). In the first stage the reduction of catalyst occurred at $600^{\circ} \mathrm{C}$, in the second the mixture of ethylene with argon was introduced into the chamber and the process proceeded at $700^{\circ} \mathrm{C}$ under atmospheric pressure. Detailed characteristics of the carbon material were given elsewhere [13].

The functionalization of CNT was performed in the gas phase using chlorine gas at $400^{\circ} \mathrm{C}$. Chlorination temperature was selected based on previously studies [14]. After $3 \mathrm{~h}$ chlorine was cut off and carbon nanotubes were cooled to the room temperature under vacuum. In the last step $\mathrm{CNT}$ were washed with acetone for $12 \mathrm{~h}$ and dried at $100^{\circ} \mathrm{C}$ for $12 \mathrm{~h}$. Finally the carbon material was treated with $5 \mathrm{M}$ $\mathrm{NaOH}$ for $3 \mathrm{~h}$ to substitute chlorine with hydroxyl groups. Thus, the obtained material was boiled in distilled water and dried at $100^{\circ} \mathrm{C}$ for $12 \mathrm{~h}$. Carbon nanotubes after chlorination and hydroxylation are denoted as $\mathrm{CNT} / \mathrm{Cl}$ and $\mathrm{CNT} / \mathrm{OH}$, respectively.

CNT/epoxy resin composites (PCs) were prepared by mixing the epoxy resin Epidian 5 (obtained from bisphenol $\mathrm{A}$ and epichlorohydrin, the number average molecular weight $\leq 700$, ORGANIKA, SARZYNA SA, Poland) with a commercially available hardener Z-1 (triethylenetetramine, ORGANIKA, SARZYNA SA, Poland) and raw or modified multiwalled carbon nanotubes. The content of MWCNTs in the epoxy matrix was in the range from $0.25 \mathrm{wt} \%$ to $2.5 \mathrm{wt} \%$. In the second step the mixture was blended using a mechanical stirrer with the rotation rate of $1900 \mathrm{rpm} / \mathrm{min}$. Liquid resin with dispersed MWCNTs was poured into specially prepared aluminum plaques which facilitated the conductivity examination of the composites. Polymer composites containing raw carbon nanotubes, carbon nanotubes after chlorination, or hydroxylation are denoted as PC/CNT, $\mathrm{PC} / \mathrm{CNT} / \mathrm{Cl}$, and $\mathrm{PC} / \mathrm{CNT} / \mathrm{OH}$, respectively.

The morphology of the raw carbon nanotubes was studied using transmission electron microscopy (Jeol JEM 3010) and the amount of metal particles embedded into the carbon material, using thermogravimetry (DTA-Q600 SDT TA Instruments). Mohr titration quantification method of chlorine introduced on the carbon nanotube surface was used to determine chloride in the filtrate after the dechlorination reaction. Dispersion of CNT in the epoxy resin matrix was investigated using optical microscope (Delta Optics). The current-voltage characteristics of the polymer composites were determined at $298 \mathrm{~K}$ for cross-conductivity. For this purpose a polymer sample (with a defined shape) was placed between metal electrodes and the current flow at a given voltage was measured. Voltage waveform was coerced using the function generator (waveform generator) Owon AG1022F. Measurements were taken on the voltage increase (voltage ramp rate) $400 \mathrm{~V} / \mathrm{s}(10 \mathrm{~Hz})$ and the amplitude of $20 \mathrm{~V}(10 \mathrm{~V} \pm)$. Current measurement was performed using a digital storage oscilloscope UTD2102CEX UNI-T. For the concentration $<1.25 \%$, conductance was measured with the static method using Sefelec M1501M teraohmmeter.

\section{Results and Discussion}

The morphology of carbon material obtained during ethylene decomposition on the iron-cobalt catalyst was studied previously and the results are presented elsewhere [13]. TEM images of the same carbon material submitted to chlorination or chlorination/hydroxylation process are presented in Figures 1(a) and 1(b), respectively. It is clearly visible that in both cases carbon existed in the form of multiwalled carbon nanotubes and the diameters ranged from 20 to $30 \mathrm{~nm}$. We did not observe any obvious differences between the samples after modification regardless of the kind of the treatment. It is worth noting that the methods used for carbon nanotube modification did not destroy the carbon nanotubes structure in contrast to commonly used methods using acids. In the TEM images catalyst particles were not visible which indicates that the catalyst particles had been removed. These observations are consistent with the calculated data based on thermogravimetric curves (Figure 2). The initial carbon material contained about $9.4 \%$ of residues. After the chlorination and chlorination/hydroxylation process about $4.6 \%$ and $3.0 \%$ of ash, respectively, remained in the samples. It means that the content of the catalyst in the carbon material decreased to $30 \%$. Despite the high degree of catalyst particle removal, the structure of carbon nanotubes was also preserved.

The functionalization degree of the samples after chlorination process was described in detail elsewhere [14]. The presence of chlorine was confirmed using Mohr titration method and the results are presented in Table 1. Comparing the sample before and after chlorination it was found that chlorine content significantly increased after the modification and equaled about $1.86[\mathrm{mmol} / \mathrm{g}]$. For the material after sodium hydroxide treatment the chlorine content was very low and equaled about $0.33[\mathrm{mmol} / \mathrm{g}]$. It indicates that during hydroxylation process chlorine atoms were substituted by hydroxyl groups.

Optical microscopy enables fast observation of the overall state of nanotube dispersion in the epoxy matrix. Figures 3(a)-3(c) show optical micrographs of the obtained composites containing $1.25 \mathrm{wt} \%$ of MWCNTs. Single and small carbon nanotube clusters with sizes less than about $10 \mu \mathrm{m}$ can be readily seen in the sample based on the raw carbon material (Figure 3(a)). Much better dispersion was obtained when multiwalled carbon nanotubes after chlorination (Figure 3(b)) or chlorination followed by a reaction with sodium hydroxide (Figure 3(c)) as a filler in the polymer composite were applied. Although a few MWCNT aggregates can still be observed, their sizes are rather small and are homogeneously distributed in the polymer matrix. It indicates that the functional groups presented on the carbon nanotube surface allow obtaining a homogeneous dispersion which is consistent with findings reported by $\mathrm{Yu}$ et al. [15]. Functionalization of carbon nanotubes improved the compatibility of the filler with the polymer, which ensured a better wetting and adhesion between both phases as well as a satisfactory distribution of the nanofiller. A surface functionalization of CNT with reactive groups may help in a better dispersion via the improvement in polymer, 


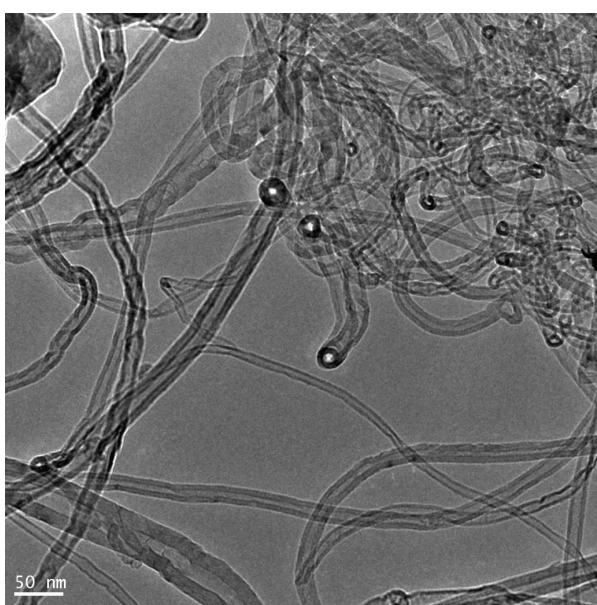

(a)

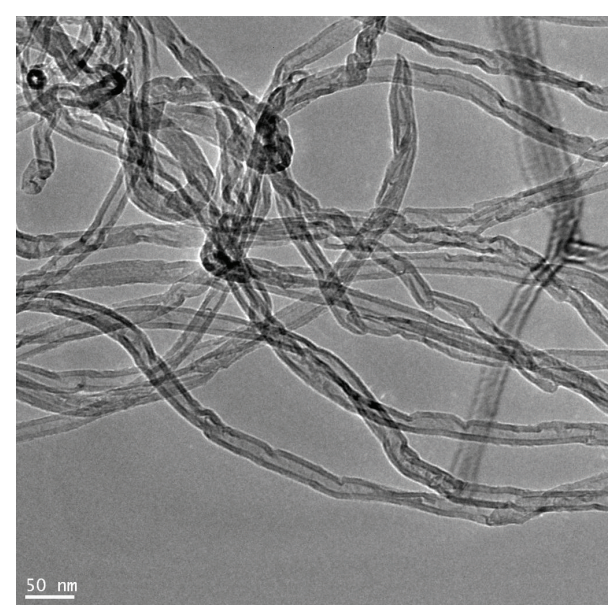

(b)

FIGURE 1: TEM images of the carbon material after chlorination (a), after reaction with sodium hydroxide (b).

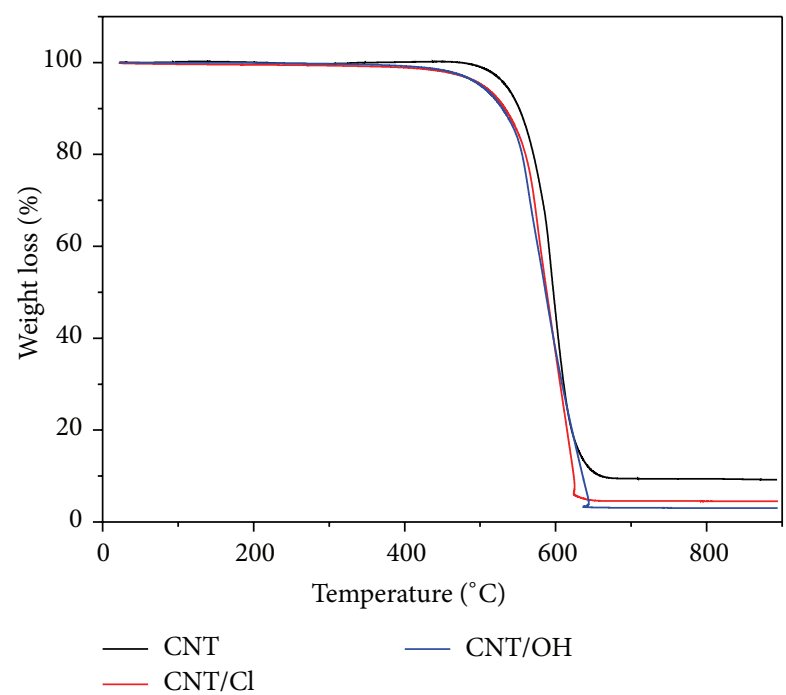

FIGURE 2: TGA curves of the carbon material obtained on ironcobalt catalysts after ethylene decomposition (a), chlorination (b), and reaction with sodium hydroxide (c).

TABLE 1: Chlorine content in the samples analyzed using Mohr titration method.

\begin{tabular}{lccc}
\hline \multirow{2}{*}{ Sample } & \multicolumn{3}{c}{ Chlorine content $[\mathrm{mmol} / \mathrm{g}]$} \\
& $\begin{array}{c}\text { Before } \\
\text { chlorination }\end{array}$ & $\begin{array}{c}\text { After } \\
\text { chlorination }\end{array}$ & $\begin{array}{c}\text { After } \\
\text { hydroxylation }\end{array}$ \\
\hline Carbon nanotubes & 0.19 & 1.86 & 0.33 \\
\hline
\end{tabular}

CNT physical interactions or even chemical bonds between functional groups and polymer chains.

For the obtained composites current-voltage characteristic was determined and presented in Figure 4. It was found that the positive and negative $I-V$ are symmetric and exhibit a nonlinear current-voltage relationship. Together with the voltage increase, the conductivity increases exponentially. It can be the result of the positive conductivity temperature coefficient of carbon nanotubes. The increase of the power emitted on the percolation paths causes their heating and leads to the increase of their conductivity. To the description $I-V$ the following equations were applied:

$$
I=U \cdot G \cdot \exp (k \cdot U),
$$

where $I$ is the current $(\mathrm{mA}), U$ is the voltage $(\mathrm{V}), G$ is the electrical conductance for $U=0 \mathrm{~V}(\mathrm{~S}), k$ is the constant, and

$$
J=E \cdot G_{0} \cdot \exp (k \cdot E),
$$

where $J$ is the current density $\left(\mathrm{A} / \mathrm{m}^{2}\right), E$ is the electric field strength $(\mathrm{V} / \mathrm{m}), G_{0}$ is the conductivity for $E=0(\mathrm{~S} / \mathrm{m})$, and $k$ is the constant.

In Table 2, the parameters of (1) and in Table 3 the electrical conductivity for $E=0$ were presented. The $G_{0}$ values were determined from (2), while for the composites containing $1.25 \mathrm{wt} \%$ of CNT from (3), which is presented below:

$$
G_{0}=G_{S} \cdot \frac{S}{h}
$$

where $G_{S}$ is the sample conductance determined by static method (S), $S$ is the sample cross-sectional $\left(\mathrm{m}^{2}\right)$, and $h$ is the sample thickness (m).

In Figure 5 the dependence of conductivity on the nanomaterial concentration is presented. It was found that at a higher concentration of raw carbon nanotubes was added to the polymer matrix; the obtained composite material demonstrated the highest electrical conductivity. In the case of composites filled with modified carbon nanotubes the higher conductivity displayed the material filled with CNTs with hydroxyl groups on the surface. Probably the nature of the surface hydroxyl groups improved the dispersion of the nanomaterials which created more percolation paths. At a lower concentration of the filler, the highest values of electrical conductivity exhibited polymer composites filled 


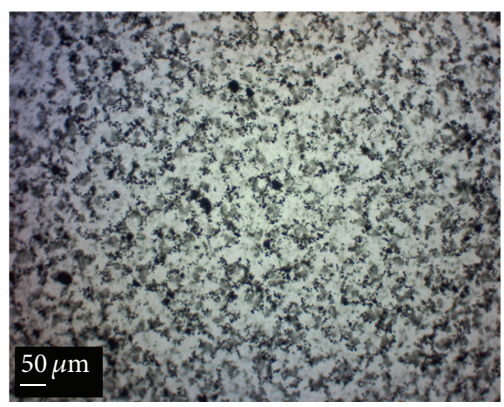

(a)

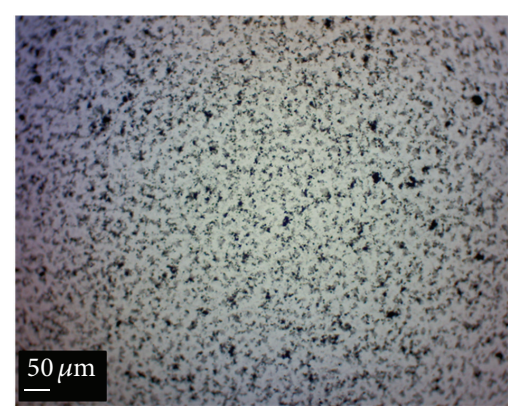

(b)

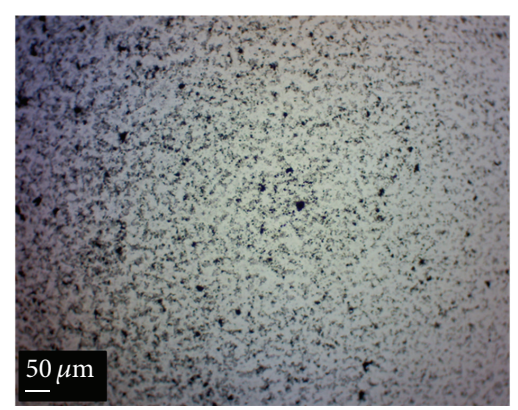

(c)

FIGURE 3: Optical micrographs of composites based on epoxy resin and $1.25 \mathrm{wt} \%$ MWCNTs: (a) before modification, (b) after chlorination, and (c) after hydroxylation.

TABLE 2: Parameters of (1).

\begin{tabular}{|c|c|c|c|c|c|c|}
\hline \multirow{2}{*}{ Filler conc., $C$ [wt $\%]$} & \multicolumn{3}{|c|}{ Constant, $k$} & \multicolumn{3}{|c|}{ Electrical conductance for $U=0 \mathrm{~V}, G[\mathrm{mS}]$} \\
\hline & $\mathrm{PC} / \mathrm{CNT}$ & $\mathrm{PC} / \mathrm{CNT} / \mathrm{Cl}$ & $\mathrm{PC} / \mathrm{CNT} / \mathrm{OH}$ & $\mathrm{PC} / \mathrm{CNT}$ & $\mathrm{PC} / \mathrm{CNT} / \mathrm{Cl}$ & $\mathrm{PC} / \mathrm{CNT} / \mathrm{OH}$ \\
\hline 2.5 & 0.028 & 0.028 & 0.028 & 110 & 2.75 & 5.72 \\
\hline 2.0 & 0.040 & 0.027 & 0.026 & 7.75 & 1.48 & 2.48 \\
\hline 1.25 & 0.026 & 0.029 & 0.028 & 0.054 & 0.058 & 0.094 \\
\hline
\end{tabular}

TABLE 3: Electrical conductivity for $E=0$; composites containing 1, 0.5 , and $0.25 \mathrm{wt} \%$ of CNT were measured using static method.

\begin{tabular}{lccc}
\hline \multirow{2}{*}{ Filler conc., $C[\mathrm{wt} \%]$} & \multicolumn{3}{c}{ Conductivity for $E=0, G_{0}[\mathrm{~S} / \mathrm{m}]$} \\
& $\mathrm{PC} / \mathrm{CNT}$ & $\mathrm{PC} / \mathrm{CNT} / \mathrm{Cl}$ & $\mathrm{PC} / \mathrm{CNT} / \mathrm{OH}$ \\
\hline 2.5 & $1.3 E-03$ & $3.2 E-05$ & $6.7 E-05$ \\
2.0 & $9.1 E-05$ & $1.7 E-05$ & $2.9 E-05$ \\
1.25 & $6.4 E-07$ & $6.8 E-07$ & $1.1 E-06$ \\
$1.0^{*}$ & $4.1 E-11$ & $6.2 E-11$ & $14 E-11$ \\
$0.5^{*}$ & $1.2 E-12$ & $1.3 E-12$ & $1.5 E-12$ \\
$0.25^{*}$ & $0.6 E-12$ & $0.4 E-12$ & $0.7 E-12$ \\
\hline
\end{tabular}

${ }^{*}$ one point measured.

with modified carbon nanotubes, especially with hydroxyl groups, in contrast to the composites filled with the raw material.

According to the thermogravimetric studies it is known that raw carbon nanotubes possess significantly more catalyst particles than the same material after modification because functionalization process enables not only changes of CNT surface but also metal removal. In a two-component system (raw carbon nanotubes containing metal particles) at a certain concentration (about $1.6 \%$ by weight), percolating pathways involving metal particles are formed. In that case the probability of percolation pathways creation is higher because they can be formed not only from carbon nanotubes but also from metal particles. It is obvious that metal has a much higher conductivity than carbon, resulting in a more rapid increase in the conductivity of the composite. It is observed as higher values of electrical conductivity for the composites filled with $2.0 \mathrm{wt} \%$ or $2.5 \mathrm{wt} \%$ of raw carbon nanotubes.
In the case of samples after modification with a lower content of better conductive catalyst particles, the probability of percolation pathway formation from metal is lower resulting in a lower conductivity of the polymer composite.

A different situation was noticed for polymer composites obtained with a lower filler concentration. Higher values of electrical conductivity were observed for the material with an addition of modified carbon nanotubes. Samples after chlorination or hydroxylation processes (with partial removal of catalyst) contained a larger fraction volume of the carbonaceous material. As a result, more percolation paths were created for modified than raw carbon nanotubes. Finally better conductivity was achieved for $\mathrm{PC} / \mathrm{CNT} / \mathrm{OH}$ and $\mathrm{PC} / \mathrm{CNT} / \mathrm{Cl}$ compared to $\mathrm{PC} / \mathrm{CNT}$ composites.

The influence of the treatment on the percolation threshold was not noticed, which is presented in Figure 5. According to the percolation theory, the static conductivity of these composites is given by [16-18]

$$
G(C) \alpha\left(C-C_{p}\right)^{n} \quad \text { for } C>C_{P} \text {, }
$$

where $C_{P}$ is the percolation threshold, $C$ the filler content, and $n$ the critical exponent. The critical exponent was determined by linearization of dependence (4) to logarithmic form $\ln G=$ $\ln K+n \ln \left(C-C_{p}\right)$. Where $n$ is the slope.

The percolation threshold $C_{P}$ occurred for all the samples in the concentration range from 0.95 to $1.2 \mathrm{wt} \%$ similarly to findings reported by Allaoui et al. [19]. The critical exponent $n$ equals $4.9,3.8$, and 3.9 for polymer composites filled with $\mathrm{CNT}, \mathrm{CNT} / \mathrm{Cl}$, and $\mathrm{CNT} / \mathrm{OH}$, respectively.

\section{Conclusions}

The effect of carbon nanotube functionalization on the epoxy resin matrix was discussed and the incorporation of chlorine 

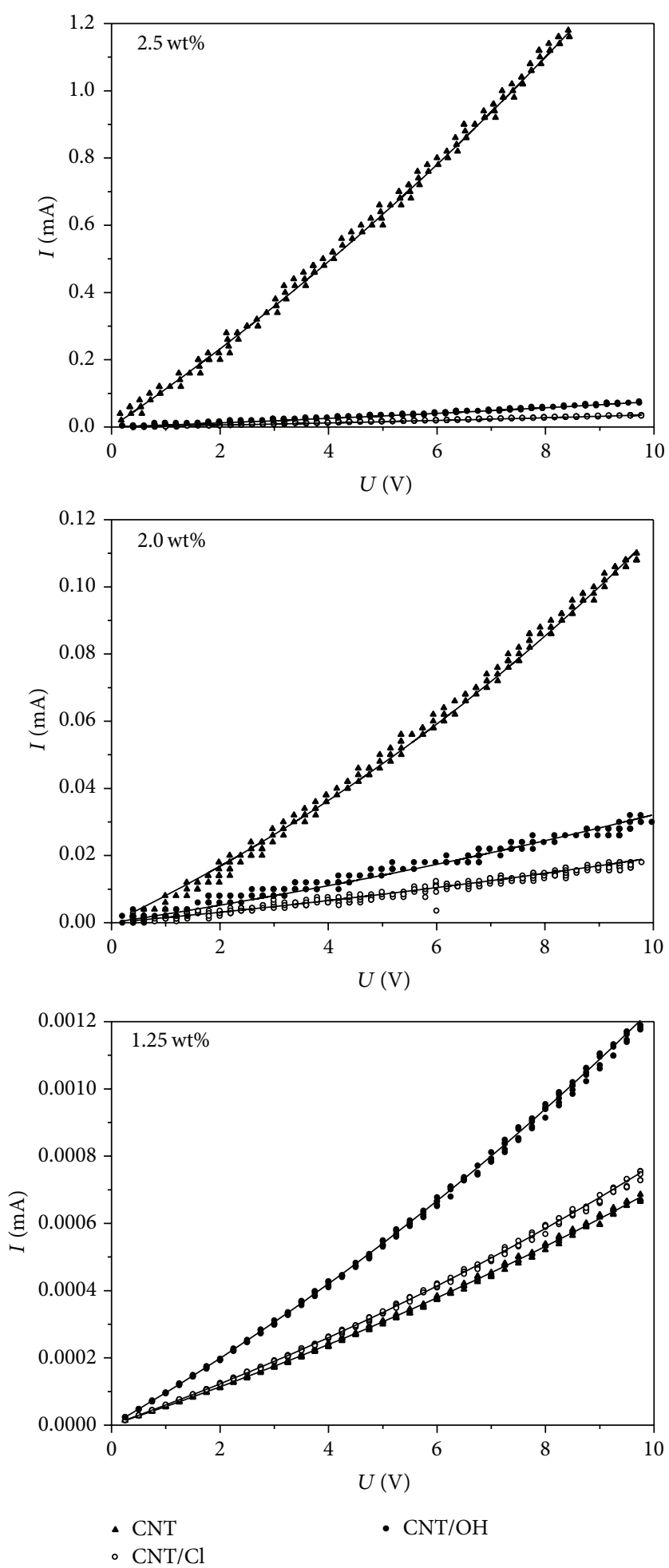

FIgURE 4: Current-voltage characteristics of the obtained composites (filler concentration 1, 0.5 and 0.25 wt $\%$ ).

and hydroxyl groups on the carbon nanotube surface was found to improve the dispersion of a filler in the polymer matrix.

For the obtained materials current-voltage characteristics were determined. They had a nonlinear character and were well described by an exponential-type equation. At a higher filler concentration, better conductivity was demonstrated by polymer composites with raw carbon nanotubes. This behavior is probably due to the coexistence of metal particles together with carbon material and their ability to create 


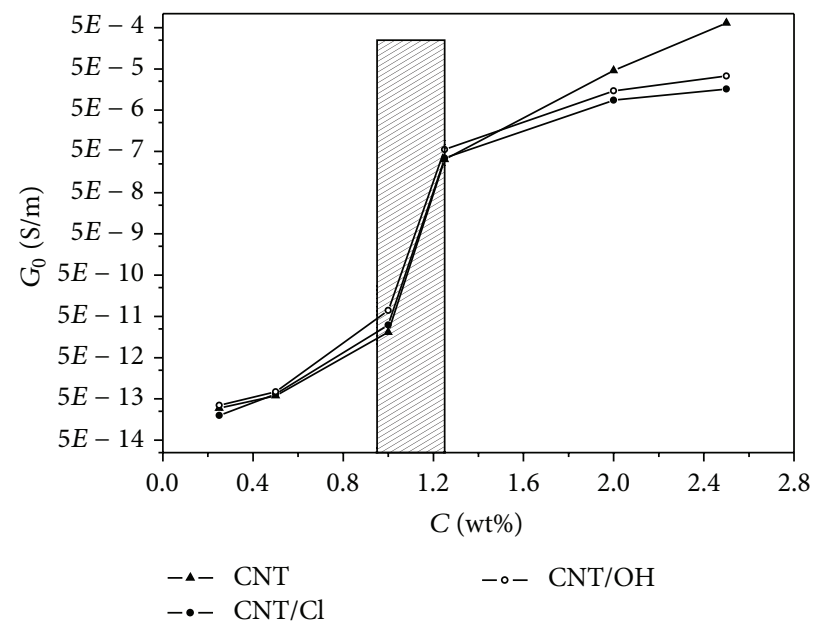

FIGURE 5: Electrical conductivity for $E=0$, composites with the filler concentration 1, 0.5, and 0.25 wt $\%$ were measured using static method.

more percolation pathways at a higher filler concentration. At a lower filler concentration, higher values of electrical conductivity were obtained for polymer composites with modified carbon nanotubes. Modified fillers containing a larger fraction volume of the carbonaceous material create more percolation paths at a lower concentration in the polymer matrix which favors a better dispersion of carbon nanotubes. For all the obtained materials the percolation threshold occurred at a concentration of about $1 \mathrm{wt} \%$.

\section{Conflict of Interests}

The authors declare that there is no conflict of interests regarding the publication of this paper.

\section{Acknowledgment}

This work was supported by Project LIDER/25/58/13/11/NCBR/2012 financed by The National Centre for Research and Development.

\section{References}

[1] Z.-M. Dang, K. Shehzad, J.-W. Zha, T. Hussain, N. Jun, and J. Bai, "On refining the relationship between aspect ratio and percolation threshold of practical carbon nanotubes/polymer nanocomposites," Japanese Journal of Applied Physics, vol. 50, no. 8, Article ID 080214, 2011.

[2] Y. Chen, S. Wang, F. Pan, and J. Zhang, "A numerical study on electrical percolation of polymer-matrix composites with hybrid fillers of carbon nanotubes and carbon black," Journal of Nanomaterials, vol. 2014, Article ID 614797, 9 pages, 2014.

[3] G. S. Nanda, R. Sravendra, W. C. Jae, L. Lin, and H. C. Siew, "Polymer nanocomposites based on functionalized carbon nanotubes," Progress in Polymer Science, vol. 35, no. 7, pp. 837867,2010

[4] K.-S. Kim and S.-J. Park, "Influence of amine-grafted multiwalled carbon nanotubes on physical and rheological properties of PMMA-based nanocomposites," Journal of Solid State Chemistry, vol. 184, no. 11, pp. 3021-3027, 2011.
[5] L.-J. Cui, H.-Z. Geng, W.-Y. Wang, L.-T. Chen, and J. Gao, "Functionalization of multi-wall carbon nanotubes to reduce the coefficient of the friction and improve the wear resistance of multi-wall carbon nanotube/epoxy composites," Carbon, vol. 54, pp. 277-282, 2013.

[6] L. Guadagno, B. de Vivo, A. Di Bartolomeo et al., "Effect of functionalization on the thermo-mechanical and electrical behavior of multi-wall carbon nanotube/epoxy composites," Carbon, vol. 49, no. 6, pp. 1919-1930, 2011.

[7] A. Zhang, J. Luan, Y. Zheng, L. Sun, and M. Tang, "Effect of percolation on the electrical conductivity of amino molecules non-covalently coated multi-walled carbon nanotubes/epoxy composites," Applied Surface Science, vol. 258, no. 22, pp. 84928497, 2012.

[8] J.-H. Lee, K. Y. Rhee, and S. J. Park, "Silane modification of carbon nanotubes and its effects on the material properties of carbon/CNT/epoxy three-phase composites," Composites Part A, vol. 42, no. 5, pp. 478-483, 2011.

[9] N. R. R. Royan, A. B. Sulong, J. Sahari, and H. Suherman, "Effect of acid- and ultraviolet/ozonolysis-treated MWCNTs on the electrical and mechanical properties of epoxy nanocomposites as bipolar plate applications," Journal of Nanomaterials, vol. 2013, Article ID 717459, 8 pages, 2013.

[10] Z. Spitalsky, D. Tasis, K. Papagelis, and C. Galiotis, "Carbon nanotube-polymer composites: chemistry, processing, mechanical and electrical properties," Progress in Polymer Science, vol. 35, no. 3, pp. 357-401, 2010.

[11] Z. Špitalský, C. A. Krontiras, S. N. Georga, and C. Galiotis, "Effect of oxidation treatment of multiwalled carbon nanotubes on the mechanical and electrical properties of their epoxy composites," Composites A: Applied Science and Manufacturing, vol. 40, no. 6-7, pp. 778-783, 2009.

[12] Y. J. Kim, T. S. Shin, H. D. Choi, J. H. Kwon, Y.-C. Chung, and H. G. Yoon, "Electrical conductivity of chemically modified multiwalled carbon nanotube/epoxy composites," Carbon, vol. 43, no. 1, pp. 23-30, 2005.

[13] I. Pełech, U. Narkiewicz, A. Kaczmarek, and A. Jędrzejewska, "Preparation and characterization of multi-walled carbon nanotubes grown on transition metal catalysts," Polish Journal of Chemical Technology, vol. 16, no. 1, pp. 117-122, 2014. 
[14] I. Pełech, R. Pełech, U. Narkiewicz, D. Moszyński, A. Jędrzejewska, and B. Witkowski, "Chlorination of carbon nanotubes obtained on the different metal catalysts," Journal of Nanomaterials, vol. 2013, Article ID 836281, 9 pages, 2013.

[15] H. Yu, J. Liu, X. Wen et al., "Charing polymer wrapped carbon nanotubes for simultaneously improving the flame retardancy and mechanical properties of epoxy resin," Polymer, vol. 52, no. 21, pp. 4891-4898, 2011.

[16] L. He and S.-C. Tjong, "Carbon nanotube/epoxy resin composite: correlation between state of nanotube dispersion and Zener tunneling parameters," Synthetic Metals, vol. 162, no. 24, pp. 2277-2281, 2012.

[17] C.-W. Nan, "Physics of inhomogeneous inorganic materials," Progress in Materials Science, vol. 37, no. 1, pp. 1-116, 1993.

[18] M. Montia, I. Armentanoa, G. Faiellac et al., "Toward the microstructure-properties relationship in MWCNT/epoxy composites: percolation behavior and dielectric spectroscopy," Composites Science and Technology, vol. 96, pp. 38-46, 2014.

[19] A. Allaoui, S. Bai, H. M. Cheng, and J. B. Bai, "Mechanical and electrical properties of a MWNT/epoxy composite," Composites Science and Technology, vol. 62, no. 15, pp. 1993-1998, 2002. 

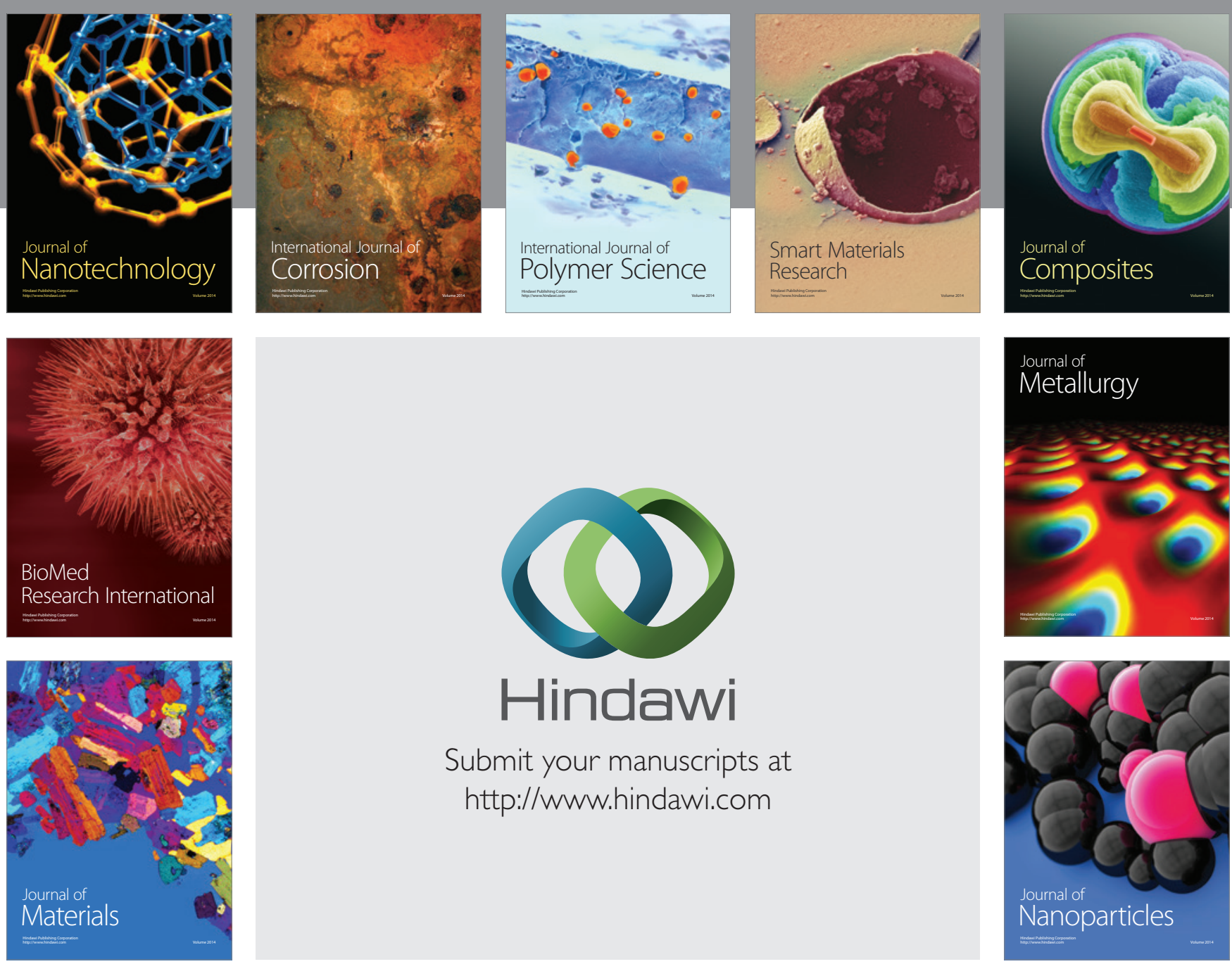

Submit your manuscripts at http://www.hindawi.com
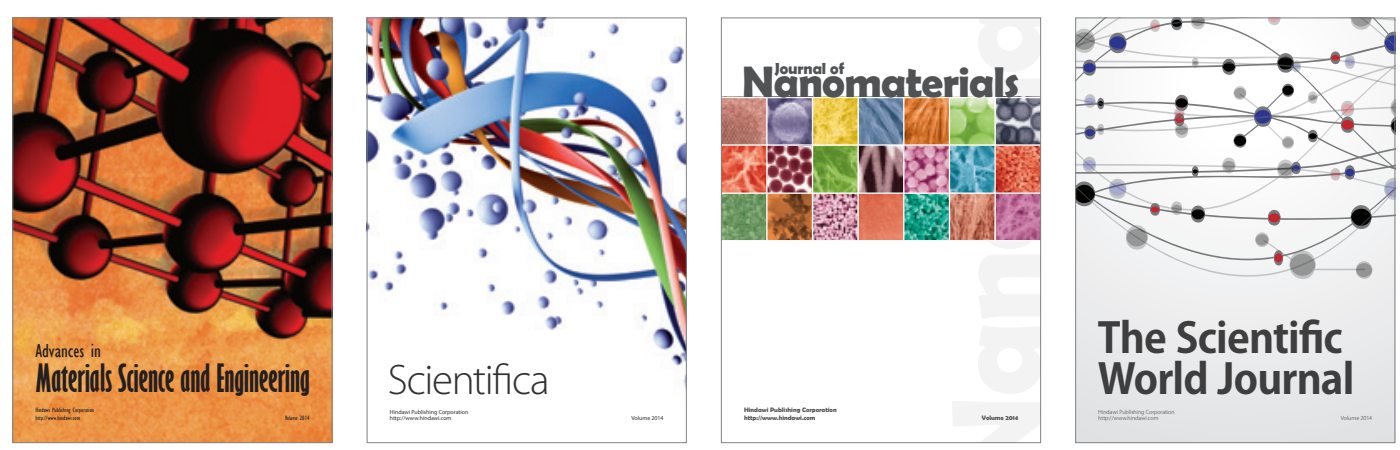

\section{The Scientific World Journal}
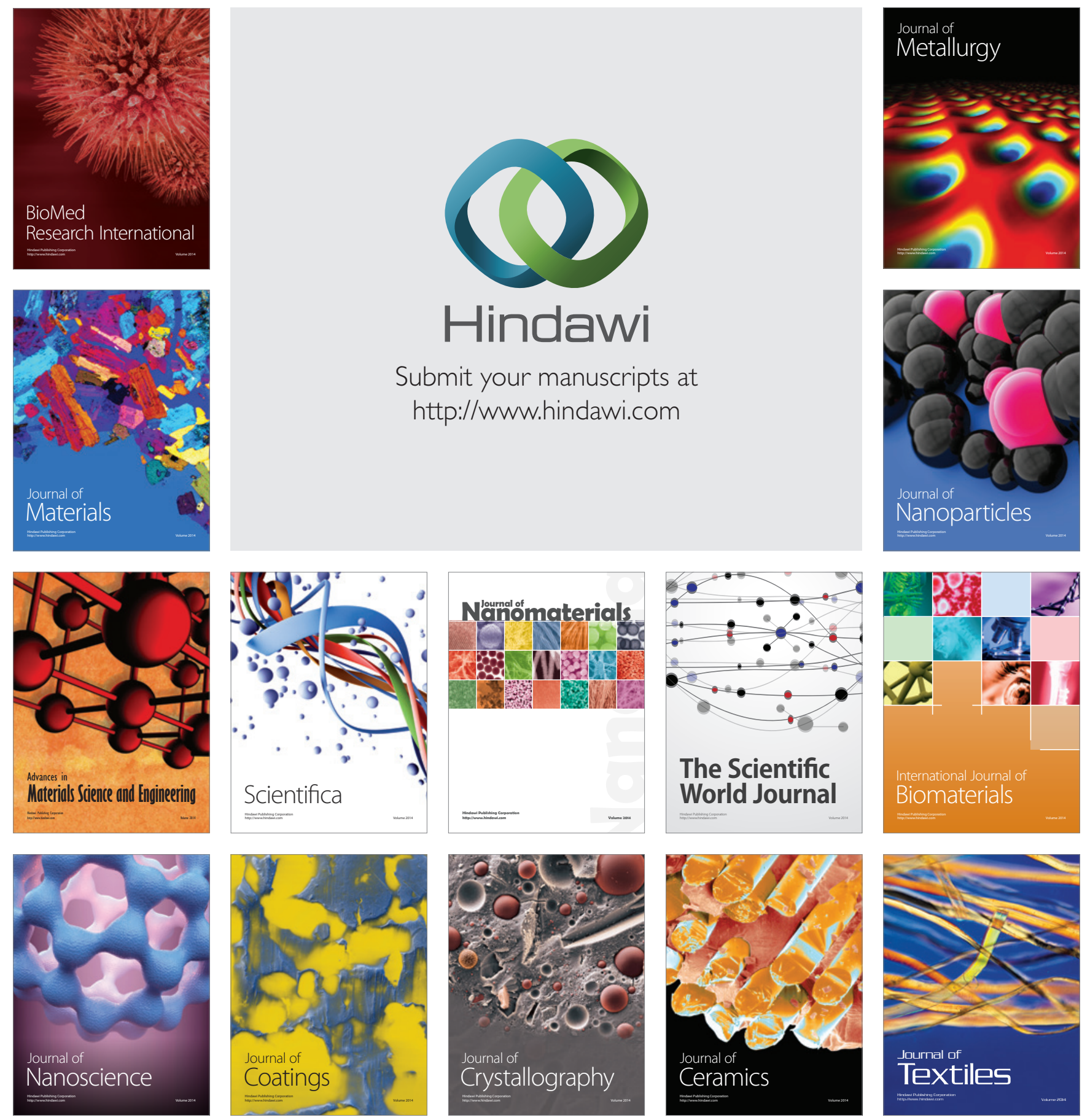